\title{
Injury prevention and control: reflections on the state and the direction of the field
}

\author{
Maria Segui-Gomez MD, ScD, (1) Mathew Miller MD, ScD(2)
}

\begin{abstract}
Segui-Gómez M, Miller M.
Injury prevention and control:

reflections on the state and the direction of the field Salud Publica Mex 2008;50 suppI I:SI O I-SI I I.
\end{abstract}

\begin{abstract}
Objective. To provide an assessment of the contours of the injury field today and to raise questions about our future direction. Material and Methods. We classified the selfreported activities of injury centers, assessed trends in injuryrelated publications in peer review journals, and compared data on current funding levels. Results. The 47 identified centers are more likely to focus on unintentional injuries and on prevention than on intentional injuries, biomechanics, acute care or rehabilitation. Injury-related publications have doubled over the past decade, yet remained dwarfed by those on other diseases. Funding for injury prevention remains incommensurate with the burden of injury. Within the injury field itself, publications and funding are not commensurate with the burden imposed by particular injuries. Conclusion. Our responsibilities as injury prevention professionals will increase not only because of the projected increase in the global burden of injury but also because of our expanded conceptualization of what the scope of injury prevention should be.The lack of clarity we project about the substantive areas of our expertise and the incommensurate funding for our efforts relative to their toll on global health represent challenges to our field's coherence and ultimate effectiveness.
\end{abstract}

Key words: injury prevention; burden; professionalism; strategic thinking

\section{Segui-Gómez M, Miller M.}

Prevención y control de lesiones por causas externas: reflexiones sobre la situación actual y futura.

Salud Publica Mex 2008;50 supl I:SI OI-S I I .

\section{Resumen}

Objetivo. Valorar el estado actual del área de la prevención de lesiones y plantear el futuro de la misma. Material y métodos. Clasificamos las actividades llevadas a cabo por diferentes centros de prevención de lesiones; recabamos información sobre la tendencia en las publicaciones en revistas científicas, y comparamos los datos sobre financiación. Resultados. Evaluamos las actividades de 47 instituciones. En general, los centros realizan actividades relacionadas con las lesiones no intencionadas y en la prevención en detrimento de las lesiones intencionales, la biomecánica, asistencia sanitaria o la rehabilitación. Las publicaciones relacionadas con el área de las lesiones se han duplicado en la pasada década, aunque siguen muy por debajo de las publicaciones de otras enfermedades. La financiación destinada a la prevención de lesiones sigue siendo desproporcionada con respecto a la carga de enfermedad. Dentro del propio ámbito de la prevención de lesiones, tanto la financiación como las publicaciones no se adecuan a la carga impuesta por diferentes tipos de lesiones. Conclusión. Nuestra responsabilidad aumenta en tanto que aumenta la carga de las lesiones sobre la población mundial y al mismo tiempo se amplía nuestra visión sobre lo que constituye una lesión. En vista de las discrepancias sobre la percepción, necesidades y escasez de financiación, hemos de estudiar con detenimiento las estrategias de futuro.

Palabras clave: prevención lesiones; accidentes; carga; profesión; estrategia

(I) European Center for Injury Prevention at Universidad de Navarra, Spain.

(2) Harvard Injury Control Center, USA.

Received on: November 20, 2007 - Accepted on: December 6, 2007 
Tnjury prevention as a field of academic inquiry and scientific knowledge is over sixty years old ${ }^{1}$ and still a child. The disciplinary boundaries, substantive foci, and philosophical mission that define our field today differ in identifiable ways from those of even a decade ago and suggest, albeit contingently, what the field may look like tens years hence. In the following pages we present measures of the magnitude and scope of the injury field, describe how our identity as a field has changed in recent decades, summarize the mission statements and active projects of organizations that self-identify as injury prevention and control centers, report summary statistics for scholarly publications on injury over the past decade, and examine available estimates of current funding of injury relative to other major causes of mortality and morbidity as well as the distribution of funding within the field itself. We are glad for the opportunity to reflect on the contours of the injury field today and to raise questions about the challenges that will shape our future.

\section{The Facts}

\section{I) Magnitude of the Injury Burden}

Sixty years ago the data available to measure rates of injury mortality and morbidity were far less sophisticated and reliable than they are today. Yet even crude comparisons of injuries today and those of half a century ago point to areas of obvious success and failure. In the developed world we have witnessed a dramatic fall in mortality due to unintentional injury, although recent reports in the US suggest that this fall may have been temporary. ${ }^{2}$ We have seen little improvement in the incidence of intentional injury (suicide and homicide), which today comprise a large proportion of all injury deaths worldwide (see below). ${ }^{3}$ In the developing world, success in reducing the toll of injury has lagged far behind those observed in more affluent societies. ${ }^{4}$

Even our greatest successes in the developed world, such as reducing motor vehicle fatality rates (a reduction which warranted the label of being one of the 10 most important public health successes in the US during the 20th century), ${ }^{5}$ are tempered by the recognition that in 2007 injuries continue to be a leading cause of death, disability and suffering. ${ }^{6}$

In their latest estimates, the World Health Organization reports approximately five million deaths worldwide in Group III conditions: road traffic "accidents", self-inflicted injuries, violence and war, falls and "other". As figure 1 illustrates, fatalities in Group III are about one-fourth of the deaths attributed to infectious diseases (group I) and about one-sixth of the deaths attributed to chronic conditions (group II). Grouped together, injuries tend to rank as the fourth to sixth as cause of death in many developed and developing countries. Table I summarizes how specific injury mechanisms rank as leading causes of death compared to rankings that attempt to capture the impact of non-fatal injuries as measured in DALYS.

Despite the preventive efforts developed to date, predictions for 2030 are for large increases in the numbers of fatal and non-fatal injuries, rising to some seven million deaths per year. Specific mechanisms of injury, including self-inflicted injury and road traffic collisions, are predicted to rise in the ranks as leading causes of death and disability. By 2030, for example, road traffic victims are expected to become the $4^{\text {th }}$ leading cause of DALYs lost. It is sobering to view the data in figure 1 , where even the most researched, intervened-upon and successfully prevented fatal injury -motor vehiclerelated fatalities- is predicted to rise.

A 2003 WHO report identified road traffic crashes (along with cardiovascular disease and tobacco) as one of three "neglected diseases" in the world because (they argued): we know the magnitude of the burden, we know the causes, and we know of the appropriate policies to address them. ${ }^{7}$ Yet, injuries remain ignored in many forums, including those that grease the wheels of funding mechanisms by both governmental and nongovernmental sources. A number of examples illustrate this point:

- A recent report on neglected diseases, defined as those diseases seen as primarily affecting people living in poverty in developing countries, and in particular in rural areas, did not mention motor vehicle injuries, suicide or homicide (or any other injury for that matter) ${ }^{8}$

- A 2007 book for health care providers in less developed environments entitled The child health care course contains no chapter to injury prevention. ${ }^{9}$

- In several countries in which injury is a leading cause of death and disability, stated health targets frequently do not include injuries in their top 10 priorities. $^{10}$

\section{II) Identity as a Field}

\section{i) How we see ourselves}

The most commonly cited definition of "injury" is physical damage resulting from energy transfer in excess of cellular tolerance. ${ }^{11}$ Traditionally, physical damage from energy transfer was considered an injury regardless of the mechanism by which it was immediately caused and 


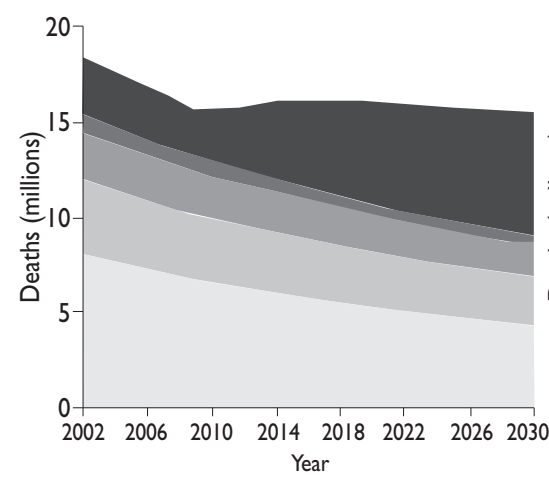

- HIV/AIDS

- Other

- Perinatal

Respiratory infections

Infectious excluding HIVIAIDS

Group I
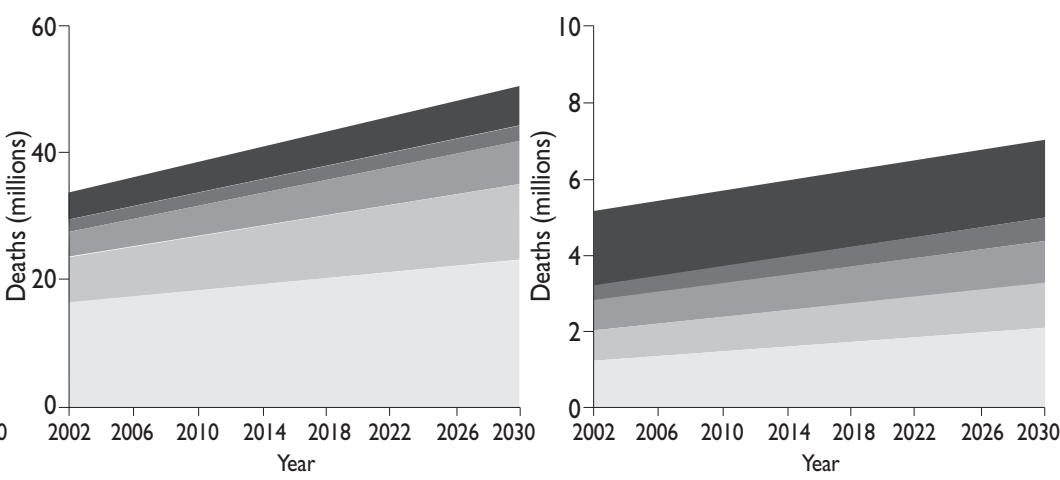

- Other

Digestive

Respiratory

Cancer

CVD

Group II
- Other

Falls

Violence and war

- Self-inflicted

Road traffic accidents

Group III

Adapted from Miniño AM, Heron MP, Murphy SL, Kochanek KD, Centers for Disease Control and Prevention. National Center for Health Statistics. National Vital Statistics System. Deaths: Final data for 2004. Natl Vital Stat Rep 2007;55(19): I-I I9. [Accessed on December I3, 2007]. Available online at: http://www. cdc.gov/nchs/data/nvsr/nvsr55/nvsr55_19.pdf.

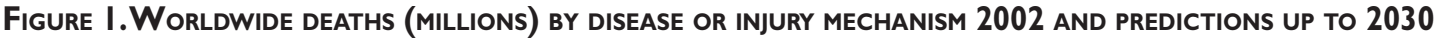

Table I

WORLD WIDE RANKING IN 2002 AND 2030 AND CHANGES FOR I5 LEADING CAUSES OF DEATH OR DALYS LOST

\begin{tabular}{|c|c|c|c|c|c|}
\hline \multicolumn{3}{|c|}{ Ranking in Deaths and change } & \multicolumn{3}{|c|}{ Ranking in DALYs and change } \\
\hline & 2002 & 2030 & & 2002 & 2030 \\
\hline Ischemic heart disease & I & $I=$ & Perinatal conditions & I & $5 \downarrow$ \\
\hline Cerebrovascular disease & 2 & $2=$ & Lower respiratory infections & 2 & $8 \downarrow$ \\
\hline Lower respiratory infections & 3 & $5 \downarrow$ & HIVIAIDS & 3 & $I \uparrow$ \\
\hline HIVIAIDS & 4 & $3 \uparrow$ & Unipolar depression & 4 & $2 \uparrow$ \\
\hline COPD & 5 & $4 \uparrow$ & Diarrhoeal diseases & 5 & $12 \downarrow$ \\
\hline Perinatal conditions & 6 & $9 \downarrow$ & Ischemic heart disease & 6 & $3 \uparrow$ \\
\hline Diarrhoeal diseases & 7 & $16 \downarrow$ & Cerebrovascular disease & 7 & $6 \uparrow$ \\
\hline Tuberculosis & 8 & $23 \downarrow$ & Road traffic accidents & 8 & $4 \uparrow$ \\
\hline Trachea, bronchus, lung cancer & 9 & $6 \uparrow$ & Malaria & 9 & $15 \downarrow$ \\
\hline Road traffic accidents & 10 & $8 \uparrow$ & Tuberculosis & 10 & $25 \downarrow$ \\
\hline Diabetes mellitus & II & $7 \uparrow$ & COPD & II & $7 \uparrow$ \\
\hline Malaria & 12 & $22 \downarrow$ & Congenital anomalies & 12 & $20 \downarrow$ \\
\hline Hypertensive heart disease & 13 & $11 \uparrow$ & Adult hearing losses & 13 & $9 \uparrow$ \\
\hline Self-inflicted injuries & 14 & $12 \uparrow$ & Cataracts & 14 & $10 \uparrow$ \\
\hline Stomach cancer & 15 & $10 \uparrow$ & Violence & 15 & $13 \uparrow$ \\
\hline$\ldots$ & & & $\ldots$ & $\ldots$ & $\ldots$ \\
\hline Nephritis and nephrosis & 17 & $13 \uparrow$ & Self-inflicted injuries & 17 & $14 \uparrow$ \\
\hline
\end{tabular}

Adapted from Miniño AM, Heron MP, Murphy SL, Kochanek KD, Centers for Disease Control and Prevention. National Center for Health Statistics. National Vital Statistics System. Deaths: Final data for 2004. Natl Vital Stat Rep 2007;55(19):I-I I9. [Accessed on December 13, 2007]. Available online at: http://www. cdc.gov/nchs/data/nvsr/nvsr55/nvsr55_19.pdf 
irrespective of the role of intent. Yet we have embraced physical transfer of energy as a defining criterion only so far: war- or terrorism-related injuries, counted as an injury outcome by the WHO, is seldom the focus of our best science or evaluations; outcomes of frequent but lower energy transfers (e.g. those common in occupational settings) get little play at our conferences.

We have greatly expanded the scope of our field over the past decade or so by including injuries with an intentional component (e.g., suicide and homicide). The prospect of this expansion was accompanied by internecine tension within the field as well as healthy debate about who we are and who we want to become (see, for example, the debates about whether the journal Injury Prevention should include articles on violence-related injuries). ${ }^{12-14}$ The erosion of the intent-based partition between injury prevention and other disciplines, chiefly those of mental health and criminal justice, stemmed from our recognition that etiologic factors identified in epidemiologic studies of unintentional injury (e.g., alcohol consumption) are cross-cutting risk factors for intentional injury. For example, increasing the minimum legal drinking age was motivated by a desire to reduce motor vehicle crashes but it also had the benefit of reducing suicide rates among 18-23 year olds. ${ }^{15}$

In affirming that it is not the fugitive attribute of intention that defines our field, we have expanded not only our opportunities but also our responsibilities since we are now obliged to grapple with issues such as the psychological harm, maldevelopment or deprivation related to the intentional use of physical force or power. ${ }^{16}$ Over the next several years we will have to contend not only with other definitional issues, such as whether to include under the injury umbrella outcomes like adverse events from medical interventions, but also with how to expand our own methodological expertise beyond the types of epidemiologic studies that have thus far largely defined our work.

\section{ii) What we claim we do}

A search of injury prevention and / or control (research) centers provides one account of who we claim to be and what we claim to do. In this section we present data derived from searching the websites of umbrella organizations such as ISVIP (International Society for Violence and Injury Prevention), SAVIR (Society for Advancement of Violence and Injury Research), and EuroSafe. We identified the member organizations and visited their websites, which led to identifying a few more organizations. In total, we identified 47 institutions related to each other in this way and for which we found information on their websites (either in English or
Spanish), although we do not assume that we identified all relevant associations (appendix A).

Our goal was to review their mission statements and their listing of active projects. The criteria we chose to use in our assessment are partly derived from the categories of actions put forward by the USA Committee on Trauma Research (precursor to the current USA CDC National Center for Injury Research). ${ }^{11}$ These include: a) conduct and support research in biomechanics, injury epidemiology and prevention, acute care and rehabilitation; b) establish injury surveillance systems and support prevention activities (i.e., implementation); and c) promote professional education and training. (We omit from this list both the establishment of clearinghouses and leading agencies and the establishment of injury research centers themselves). In addition, we assessed whether their research activities focused on motor vehicle, homicide, suicide or others and whether the centers reported a multidisciplinary composition.

The assessment of the areas of work was particularly challenging because reporting on the websites is neither comparable between sites nor comprehensive or exhaustive. There is variation across all possible dimensions. For example, some centers claim to have local and others international interests, some focus on children, others on rural injuries, and others on occupational issues. These limitations notwithstanding, figure 2 shows that practically all the reviewed centers reported training activities and a majority reported a multidisciplinary approach to injury prevention and research efforts. Within research efforts, more centers focus on prevention than on biomechanics or rehabilitation; most claim at least one ongoing research project on motor vehicle safety or other unintentional injuries.

\section{iii) How we are seen (or not seen) by others}

The terms used by the WHO to describe some injuries (e.g, traffic "accidents") reflect a shortcoming in our efforts to convince others that injuries are patterned and amenable to measurement -and therefore, no more an accident than the occurrence of cancer or infectious disease. Just how indistinct or, at best, fractured our field is in the eyes of the WHO is reflected by the difficulty we personally had identifying those WHO collaborating centers involved in injury prevention activities. In order to identify how many of the nearly $900 \mathrm{WHO}$ collaborating centers worldwide have injury prevention as a focus, we needed to individually search in their global database ${ }^{17}$ for "injury", "safety", "violence", "home and leisure", and "accident" to come up with what we identified as the 40 centers with expertise in our area (depending upon whether we want to include 


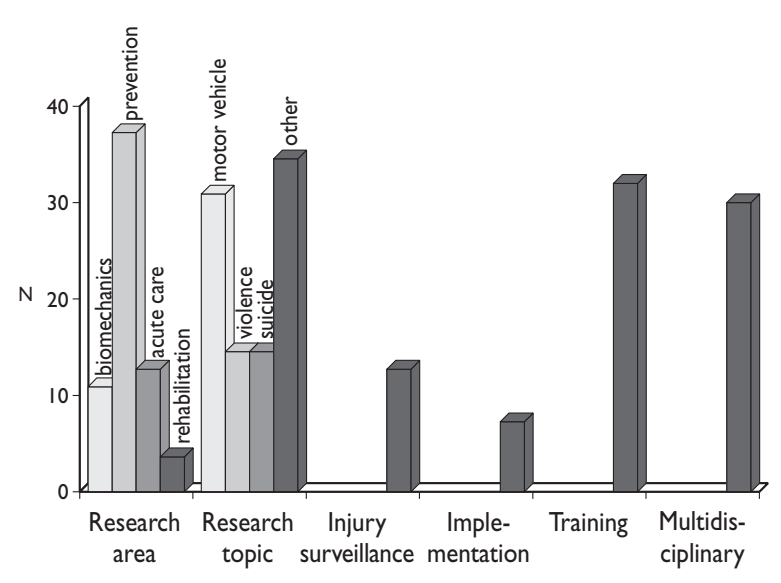

Note: All centers were assessed by two independent reviewers. Centers were counted as conducting activities in any given dimension if they reported at least one example of such activity. "Violence" counts exclude "suicide". "Other" includes all other unintentional injuries or occupational injuries. Scope, primary areas and populations of interest (data not presented in graph) and multidisciplinary approach (presented in graph) were extracted from mission statements.

Figure 2. Self-Reported activities in Selected Injury Centers around the world over a five years period, APPROXIMATELY 2002-2007. $(N=47)$

nuclear-related injuries or adverse events in the count, otherwise 32) (appendix B) (Interestingly, 32 of these centers had not been identified in the search presented in the previous paragraph, maybe another sign of the fragmentation in the field.)

We do not fault the WHO for failing to discern cohesion where no obvious cohesion exists. Rather, the difficulty identifying centers of injury research and practice reflects the fragmentary nature of the injury field itself. This fragmentation may also help explain, in part, why injuries are not as conspicuously apparent to the public, public health journals and funding institutions as would be merited by the toll of injury measured in any of a number of ways. How, after all, can we expect "outsiders" to intuitively see the common thread of energy releases as the underlying etiological mechanism uniting the different areas of injury prevention, when we ourselves have a less than integrated sense of who we are?

In another attempt to evaluate how others see us, we reviewed publications from 1997 to 2006 in the three journals with the highest impact factor in the area of Public Health and Medicine (New England Journal of Medicine, Journal of American Medical Association and Lancet). Our search in Pub Med contained the terms motor vehicle injuries, poisoning, falls, suicide and homicide. The distribution by injury mechanism of the 545 identified publications (7\% of all publications in these journals) is seen in figure 3 . We wonder whether the readers of these widely distributed journals realize these publications all relate to injury and whether the authors themselves would identify their focus as "injury prevention".

It seems to us that an important and open question is whether the common thread of "energy release" or "(possible) psychological harm" is strong enough to hold us together in the years to come and, by extension, whether the mission of reducing the burden of injury and violence is better served by striving for greater intellectual and political cohesion among those studying injury today or by redirecting our energies to promote members of other established fields to take a greater interest in injury outcomes. These two strategies are not generically antagonistic and indeed we believe that these two goals can be pursued simultaneously. On the other hand, how we should distribute our efforts in service of each of these aims is unclear and, to our minds, a question that needs to be more openly discussed.

\section{III) Production}

\section{i) Publications}

Our communications during the $9^{\text {th }}$ World Conference on Injury Prevention should serve as a snapshot of our current activities. We counted the 1200 English or Spanish-accepted abstracts according to the self-reported categories chosen by the submitting authors. Researchrelated submissions lead the pack with $27 \%$ involving transport safety, 20\% violence (onto others), $15 \%$ other unintentional injuries, 5\% acute care and rehabilitation, and 3\% self-inflicted violence (another 7\% works were about occupational injuries, but these could belong to several of the above presented categories). An additional $10 \%$ of the communications relate to methodological advances and development of injury surveillance systems, $7 \%$ to capacity building, and $6 \%$ to policy issues (Martha Hijar, personal communication).

Peer-reviewed publications are another way to document our work. Thus, we conducted another Pub Med search using the terms cancer, cardiovascular disease, respiratory illness or disease, infectious disease (including AIDS), and injury. Since we did not restrict the search to papers written in English, our counts include publications in other languages with an abstract in English. In addition, we narrowed the search by adding the term "prevention" to all categories. As seen in figure 4 , the number of injury and injury prevention 


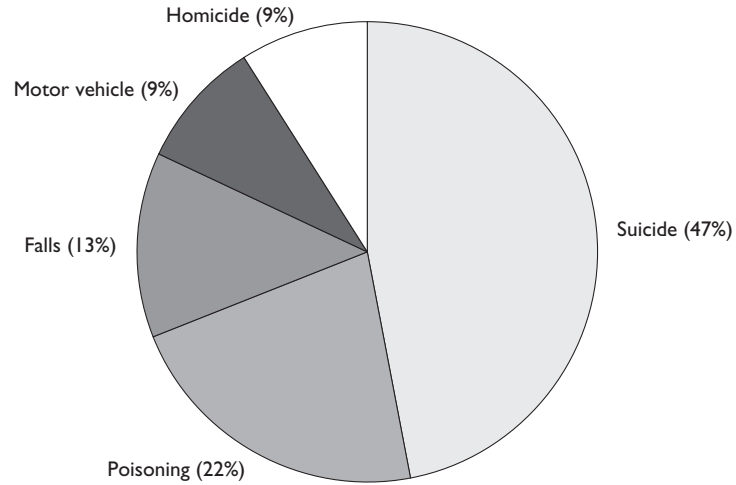

Figure 3. Publications With injury-related terms in abstract or titLe IN THREE JOURNALS (NEW ENGLAND Journal of Medicine, Journal of the American Medical Association AND LANCET) BY MECHANISM OF INJURY AS INDICATED IN KEY WORDS OR TERMS CONTAINED IN TITLE, ABSTRACT OR KEYWORDS. 1997-2006 $(N=525)$

publications in PubMed has almost doubled since 1997 (rising from 427 to 872). Over this same time period, publications in cardiovascular disease and cancer more than quadrupled. In absolute terms, publications about injury prevention are dwarfed by those focusing on car-

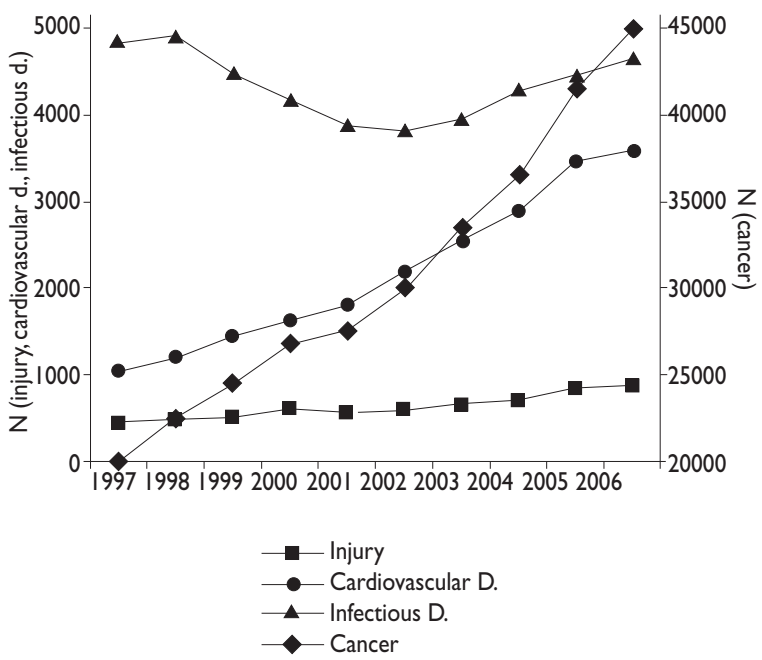

Figure 4. Publications related to prevention in any journal listed in PubMed by disease as identified by KEYWORDS OR TERMS CONTAINED IN TITLE, ABSTRACT OR KEYWORDS. 1997-2006 diovascular disease, cancer, and especially those about infectious diseases.

ii) Training

Another measure of our productivity and viability as a field is how well we have attracted students into the injury profession. Graduate-level courses in injury prevention ${ }^{18}$ are offered at many universities around the world and even undergraduates are now exposed to the science of injury prevention. ${ }^{19}$ There are, however, no doctoral or master programs in injury prevention per se. Other potentially useful metrics, such as the number of students who concentrate their graduate level theses in injury related topics, were not readily available. Membership in professional organizations is another proxy of commitment to a field which, if accurate, may be a harbinger of lean times to come. For example, the membership of the Injury Control and Emergency Health Section of the American Public Health Association has slightly decreased over the past years (Susan Scavo Gallagher, personal communication).

\section{Resources}

Our identity and productivity is shaped by the resources (both human and economic) we secure to conduct our work. The disproportion between the health burden of conditions and money devoted to investigate them was first highlighted in the early 1980s in a publication focusing on the USA. ${ }^{20} \mathrm{Almost} 30$ years later, the data indicate that we are still far from securing funding proportionate to the toll of injury. ${ }^{21}$ Our own search suggests that the discrepancy applies to the toll of injury relative to that of other major causes of mortality and morbidity (e.g., cardiovascular disease, cancer or infectious diseases) and to the toll of different injury mechanisms within injury itself. It seems to us that we undermine our claim for the former to the extent that we do not take seriously the imbalances in the latter.

Although data on funding are hard to find, table II illustrates our best effort to characterize research budgets. In the US, injury research gets less than $5 \%$ of the joint budgets of the USA National Health Institute $(\mathrm{NIH})^{22}$ and Centers for Disease Control and Prevention (CDC), ${ }^{23}$ an amount approximately 15 times smaller than the condition with the largest budget: infectious disease. This is an optimistic reading of our situation, since the NIH injury-related funding includes funding for adverse effects/medical errors, a topic that sits on the edge of what "belongs" to our scope of interest.

The figures for Europe are even more elusive. Shown in table II are the amounts devoted to research and 
Table II

\section{Funding budgets by USA National Institute of Health (NIH) and Centers for Disease Control and Prevention (CDC) and European Directorate General for Health and Consumers Affairs (DG SANCO)}

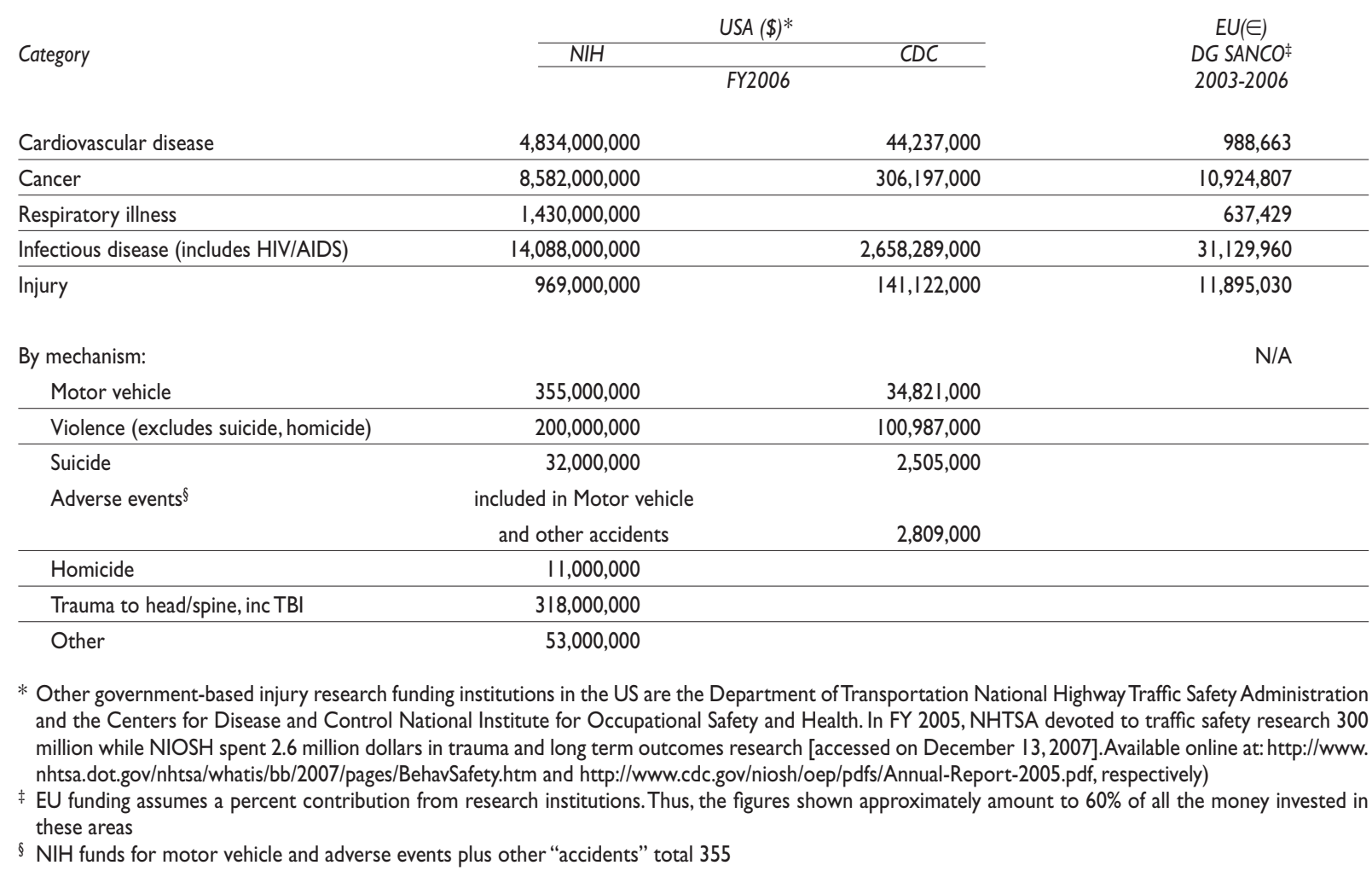

Sources: Committee on Injury Prevention and Control. Division of Health Promotion and Disease Prevention. Institute of Medicine. Reducing the Burden of Injury:Advancing Prevention and Treatment. Bonnie RJ, Fulco CE, Liverman CT, eds. Washington DC: National Academy Press, 1999

National Institute of Health. Estimates of Funding for Various Diseases, Conditions, Research Areas. Available online at: http://www.nih.gov/news/ fundingresearchareas.htm

Centers for Disease Control and Prevention. Budget figures. Available at: http://www.cdc.gov/search.do?q=budget+president\&btnG.x=0\&btnG.y=0\&sort=dat e\%3AD\%3AL\%3Ad I \&ud= I\&oe=utf8\&ie=utf8

implementation programs by condition by the agency responsible for Public Health in the European Union. ${ }^{24}$ There is injury-related research in other agencies (for example, funding for motor vehicle safety from the agency responsible for Transport). However, determining how much money actually goes into this type of research is very difficult from the publicly available files.

Within the injury field itself, the distribution of funding is also not proportionate to the burden imposed by particular injury subgroups. Consider the case for funding directed towards suicide as an injury compared to that for all other funding for intentional injury (table II, bottom part). As these data indicate, funding for suicide constituted approximately $2 \%$ of all dollars spent on intentional injuries by the CDC in 2006. Moreover, injury related, population-based research on suicide is not to an appreciable extent being supported by other agencies that conduct suicide research as these agencies have been largely governed by a research agenda in thrall to a medicalized model of suicide etiology, prevention and treatment. Indeed, one of the impediments to attracting better funding for population based approaches to preventing suicide is the failure to see injury prevention approaches, such as lethal means restriction, as critically important to suicide prevention strategies.

\section{Limitations}

This paper is meant to stimulate discussions among and between junior and senior colleagues in regards to the 
immediate future of our field. We have tried to inform this discussion by providing data we found relevant. Our figures are limited by a number of factors, such as their availability in either English or Spanish, the instruments used in our search (computerized records such as PubMed counts, websites), the difficulties associated with finding funding information, and the different standards used by researchers and research centers in reporting on their activities. Despite our hope and efforts to portray a global picture of our field, we found little data on activities in areas such as Africa, Asia, and Central and South America. We acknowledge that some of chosen criteria are arbitrary, but we have aimed to being explicit about them. If data that counter some of our interpretations are uncovered we would be delighted to hear about it.

\section{Conclusions}

The burden of injury is growing and there is much to do. In the course of writing this paper we have identified many dedicated individuals and organizations that are well situated to do this work. Indeed, at least 79 institutions around the world see themselves as committed to injury-related research and we note with special appreciation that 1500 professionals will be attending the $9^{\text {th }}$ World Conference.

Having taken stock of our field, we believe that there are reasons to be optimistic about our potential if we take seriously our obligation to think closely about our responsibilities across the three dimensions we have considered herein: the scope of our substantive charge, the priorities we accord types of injuries within our scope, and the strategies we pursue to broaden and deepen the methodological expertise among members of our field even as we strive to collaborate with experts in related areas of scientific inquiry.

As professionals, we in the injury field possess a number of strengths that should steady our resolve to confront the challenges outlined in our paper: a) we know well how to characterize injury and injury severity thanks to the development on injury coding systems; b) we believe in a conceptual model that separates injuries from the (possibly injurious) event to which they are temporally linked and to the exposure that led to that event; c) philosophically we favor structural and environmental changes that apply to all population as opposed to an individualistic-oriented approach to prevention; d) many of us have been trained in identifying the epidemiological and biostatistical tools that best fit the nature and distribution of our data; and e) we have historically developed alliances and working relationships with professionals of other disciplines as we understand injuries to be a complex phenomenon.

Yet, to secure our success we need to learn from the strategies pursued by other fields that will enable the injury field to most effectively meet the particular challenges herewith outlined. One skill we need to develop is how to become more persuasive advocates of the preventability of injuries and violence and to link the idea of preventability to research needs in terms that resonate with the missions of potential funders -governmental and otherwise. Even as importantly, we need to produce the research that demonstrates preventability to discus how best to integrate more intervention research specialists amongst us, and to secure greater funding and status for evaluative research. We need to reevaluate the role of behavioral sciences in injury prevention, and we need to develop injury and violence-specific curricula as well as to foster the use of injury and violence related examples into the courses in other disciplines, especially those that are focused on methodological innovation.

Our goal in writing this article was not to reprise the many excellent papers that have documented the structural, political, economic and intellectual developments that have led to the establishment of injury prevention as a recognized field of scientific inquiry. ${ }^{1,21}$ Neither did we set out to pay well-deserved homage to the individuals and organizations largely responsible for the success of injury prevention. Rather, we hoped to hold a mirror up to the injury field itself, to look at the image we project to the world at large and to attempt to discern, if only dimly, what we need to attend to right now to look our best in the years to come.

\section{Acknowledgments}

We appreciate Martha's Hijar willingness to have this piece published in this monographic number of Revista de Salud Pública de México and the permission from the editorial to have a Spanish translation freely downloadable from the following website (www.unav.es/ecip). We thank Susan Scavo Gallagher for her comments to a previous version of this manuscript. We also want to thank Montserrat Ruiz-Perez who assisted with the editing of the manuscript both in English and Spanish. We would also like to thank James Mercy for his help pointing us to data sources for injury funding. Last, we are in debt with Eduardo del Pozo de Dios who assisted us with some of the queries needed to complete this paper. Partial funding for the development of this manuscript comes from Mutua Montañesa (MSG). 


\section{References}

I.Waller JA. Public health then and now - reflections on a half century of injury control.Am J Public Health 1994;84(4):664-670.

2. Increases in age-group-specific injury mortality, US 1999-2004. MMWR 2007;56:128I-I284

3. Miniño AM, Heron MP, Murphy SL, Kochanek KD, Centers for Disease Control and Prevention. National Center for Health Statistics. National Vital Statistics System. Deaths: Final data for 2004. Natl Vital Stat Rep 2007;55( (19): I-I 19. [Accessed on December 13, 2007]. Available online at: http://www.cdc.gov/nchs/data/nvsr/nvsr55/nvsr55_19.pdf.

4. Mathers CD, Loncar D. Projections of global mortality and burden of disease from 2002 to 2030. PLOS Med 2006;3:20I I-2029.

5. Centers for Disease Control and Prevention. Ten great public health achievements. MMWR 1999;48(I2):24I-243. [Accessed on Jan 30, 2007]. Available online at: http://www.cdc.gov/mmwr/preview/ mmwrhtml/00056796.htm.

6. World Health Organization. World Health Statistics 2007. France:World Health Organization, 2007. [Accessed on Nov I, 2007]. Available online at: http://www.who.int/whosis/whostat2007/en/index.html.

7.World Health Organization. The World Health Report 2003: Shaping the Future. Geneva:World Health Organization, 2003. [Accessed on Jan 30, 2007]. Available online at: http://www.who.int/whr/2003/en/.

8. Hunt P, Bueno de Mesquita K, Oldring L. Neglected diseases: A human rights analysis. Social, economic and behavioral research. Special Topics $\mathrm{N}^{\circ}$ 6.Geneva:World Health Organization, 2007. [Accessed on Nov I, 2007]. Available online as PDF file [64p.] at: http://www.who.int/tdr/publications/ publications/pdf/seb_topic6.pdf.

9. Woods D. Child Health Care:A learning programme for professionals. Version I.0.I Updated 23 August 2007 Awerbuck D, ed. Eduhealthcare, 2007.

10. Minister of Health, New Zealand Government. Moving towards healthier futures 2007/08. Wellington, 2007. [Accessed on Nov I, 2007]. Available online as PDF file [48p.] at: http://www.moh.govt.nz/moh. nsf/pagesmh/6635/\$File/health-targets-aug07.pdf.

I I. National Committee for Injury Prevention and Control. Injury Prevention: meeting the challenge.Am J Prev Med 1989;5(3, supp I):297.
12. Rivara FP. Looking to the future. Inj Prev 1998;4(3): I68-169.

13. Pless IB.Violence in the journal. Inj Prev 1999;5(I):I-2.

14. Fisher L. Traditional public health injury control does not apply to violence. Inj Prev 1999;5(I):I3-14.

15. Birckmayer J, Hemenway D. Minimum age drinking laws and youth suicide, 1970-1990. Am J Public Health 1999;89(9): 1365-1368.

16. World Health Organization.WHO report on violence and health. Geneva:World Health Organization, 2002. [Accessed on Jan 30, 2007]. Available online as PDF file at: http://www.who.int/violence_injury_ prevention/violence/world_report/en/full_en.pdf.

17. World Health Organization.WHO Collaborating Centers Database. Available at http://www.who.int/collaboratingcentres/database/en/ 18. Association of Schools of Public Health, Centers for Disease Control and Prevention. Summary of Research, Teaching, Training, Practice: Injury Prevention and Control. Injury Prevention and Control in Accredited Schools of Public Health: 2002-2003. Association of Schools of Public Health, 2004.

19.Villaveces A, Kammeyer JA, Bencevic H. Injury prevention education in medical schools: An international survey of medical students. Inj Prev 2005; I I (6):343-347.

20. Hartunian N, Smart C, Thompson M. The incidence and economic costs of major health impairments. Lexington, MA: Lexington Books, I981. 21. Committee on Injury Prevention and Control. Division of Health Promotion and Disease Prevention. Institute of Medicine. Reducing the Burden of Injury:Advancing Prevention and Treatment. Bonnie RJ, Fulco CE, Liverman CT, eds. Washington DC: National Academy Press, 1999. 22. National Institute of Health. Estimates of Funding for Various Diseases, Conditions, Research Areas. [Accessed on Oct 30,2007]. Available online at: http://www.nih.gov/news/fundingresearchareas.htm.

23. Centers for Disease Control and Prevention. Budget figures. [Accessed on Oct 30, 2007]. Available at: http://www.cdc.gov/search. do? $q=$ budget + president\&btnG. $x=0 \& b \operatorname{tnG} . y=0 \&$ sort $=$ date\%3AD\%3AL\%3A $d I \& u d=I \& o e=u t f \& \& i e=u t f 8$.

24. European Commission. DG Health and Consumer Protection. List of Projects funded for years 2003-2006. [Accessed on Oct 30, 2007]. Available at: http://ec.europa.eu/health/ph_projects/action I_en.print.htm. 


\section{Appendix A \\ (RESEARCH) INJURY CONTROL OR PREVENTION CENTERS AROUND THE WORLD}

Name of Institution
Website (accessed last October 2007)

www.monash.edu.au/muarc

www.acicr.ualberta.ca

www.kfv.at/index.php?id=496

www.gwemed.edu/reagan/initiatives/cip.html

www.circl.pitt.edu

www.jhsph.edu/lnjuryCenter/index.html

www.ccri.net/ccri/centers/injuryResearch

www.albany.edu/sph/injury/injury_3.html

www.colorado.edu/cspv

wwwl.umn.edu/crpc

www.cisalva.univalle.edu.co

www.childrenssafetynetwork.org/about/default.asp

psy.psych.colostate.edu/CICRC

www.phs.ki.se/socmed

www.em.emory.edu/research_public.html

www.unav.es/ecip

www.uphs.upenn.edu/ficap

depts.washington.edu/hiprc

www.hsph.harvard.edu/hicrc

www.iapa.ca

www.lifespan.org/hch/services/ipc

www.ipn.org.nz

www.public-health.uiowa.edu/iprc

www.iprc.unc.edu

www.otago.ac.nz/ipru

www.injuryresearch.bc.ca

www.mcw.edu/display/router.asp?docid=| 442

www.irmrc.unsw.edu.au

www.irsst.qc.ca

www.intermountaininjury.org

www.kiprc.uky.edu

www.autohazardinfo.org

www.pire.org/index.asp

www.paraffinsafety.org

www.nisu.flinders.edu.au

www.surgery.ucsf.edu/sfic

www.ph.ucla.edu/scipre

www.oshc.org.hk/eng/about_us/prospect.asp

www.rospa.com

www.iitd.ernet.in/tripp

www.umtri.umich.edu/news.php

www.uab.edu/icre

www.med.umich.edu/em/injuryresearch/lnjuryResearch.htm www.hsrc.unc.edu/index.cfm www.hsc.wvu.edu/icrc

Agcenter.ucdavis.edu 


\section{Appendix B \\ WHO COLLABORATING CENTERS THAT DEAL WITH INJURIES BY KEYWORD UNDER WHICH THEY ARE LISTED}

\begin{tabular}{lll} 
Keyword & Name of Institution & Website (as listed by WHO) \\
Accident & All-Russian Center of Emergency \& Radiation Medicine & www.arcerm.spb.ru \\
\hline & Institut National de Recherche et de Sécurité pour la Prévention des Accidents \\
& du Travail et des Maladies Professionnelles & www.inrs.fr \\
\hline Institut National de Recherche sur les Transports et leur Sécurité & www.cc-oms.inrets.fr \\
\hline Institute of Radioprotection \& Dosimetry, Brazilian Nuclear Energy Commission & \\
\hline & Research Centre of Radiation Medicine \& Burns, Ministry of Health & www.veiligheid.nl \\
Home and leisure & Consumer Safety Institute & www.sph.emory.edu/CIC \\
\hline \multirow{2}{*}{ Injury } & *Center for Injury Control, Rollins School of Public Health, Emory University & www.inspq.qc.ca/ccOMS/SecuriteTrauma \\
\hline Centre de Santé publique Sécurité dans les Milieux de Vie & \\
\hline *Centre for Neurotrauma Prevention, Critical Care \& Rehabilitation, Karolinska Hospital & \\
\hline \& Institute & \\
\hline Department of Epidemiology, National Institute of Mental Health and Neuro-Sciences & \\
\hline Department of Neurotrauma Care Division of Neurotraumatology-Neurosurgery, & \\
\hline Bufalini Hospital & www.iapa.ca \\
\hline *Industrial Accident Prevention Association & www.iccu.or.ug \\
\hline Injury Control Centre, Makerere University Medical School & \\
\hline Institute for Social and Health Sciences, University of South Africa & \\
\hline London School of Hygiene and Tropical Medicine & www.cdc.gov/ncipc \\
\hline National Center for Injury Prevention \& Control, Centers for Disease Control \\
\hline \& Prevention (CDC)
\end{tabular}

Safety Canadian Centre for Occupational Health \& Safety www.ccohs.ca

Department of Occupational Medicine, Istituto Superiore per la Prevenzione e la Sicurezza del Lavoro

Department of Occupational Safety and Health, Clinica del Lavoro "Luigi Devoto" $\quad$ www.who.int/whocc/www.cdldevoto.it

*Division of Social Medicine, Department of Public Health Sciences, Karolinska Institute $\quad$ www.phs.ki.se/csp/index_en.htm

Federal Institute of Occupational Safety \& Health, Bundesanstalt für Arbeitsschutz und Arbeitsmedizin

Fundação Jorge Duprat Figueiredo de Seguranca e Medicina do Trabalho, Ministry of Labour \& Social Welfare

Health \& Safety Laboratory

International Centre for Research Promotion and Informatics, National Institute

of Occupational Safety and Health

Joint Commission on Accreditation of Health Care Organizations

National Centre for Quality Assessment in Health Care

National Institute for Occupational Safety \& Health, Centers for Disease Control

and Prevention (CDC)

National Institute of Psychiatry "Ramon de la Fuente Muniz"

Office of the Australian Safety and Compensation Council, Department of Employment

and Workplace Relations

School of Public Health, Fudan University

www.baua.de/

*Transportation Research \& Injury Prevention Programme, Centre for Biomedical

Engineering, Indian Institute of Technology

Tunisian Institute for Occupational Health and Safety, Ministry of Social Affairs and Solidarity

www.fundacentro.gov.br

www.hsl.gov.uk

www.jniosh.go.jp

www.jcaho.org

www.cmj.org.p

www.cdc.gov/niosh www.inprf.org.mx

www.dewr.gov.au

www.shmu.edu.cn

www.iitd.ac.in/tripp

\begin{tabular}{lll} 
Violence & Center for the Study of Violence - Núcleo de Estudos da Violência, University of Sao Paulo & www.nev.prp.usp.br \\
\hline Centre for Public Health, Liverpool John Moores University & www.cph.org.uk \\
\hline Centro de Investigación en Sistemas de Salud, Instituto Nacional de Salud Pública & www.insp.mx \\
\hline *entro de Investigaciones de Salud y Violencia, Facultad de Salud, Universidad del Valle & www.cisalva.univalle.edu.co \\
\hline *Monash University Accident Research Centre & www.general.monash.edu.au/muarc \\
\hline The National Council for Family Affairs & www.ncfa.org.jo
\end{tabular}

*Also listed in appendix A

Source:Accessed online last on November 15 2007: www.who.int/collaboratingcentres/database/en 